\title{
Avaliação do método de Lambert-Beer para estimativas de índice de área foliar no cerrado Mato-Grossense
}

O estudo foi desenvolvido no parque urbano Mãe Bonifácia, um fragmento de cerrado, na cidade de Cuiabá/MT, entre outubro/2014 e setembro/2015, com objetivo de avaliar a eficiência do modelo matemático de Lambert-Beer para estimativas de índice de área foliar (IAF $\mathrm{L}_{\mathrm{LB}}$ ). Os dados de radiação fotossinteticamente ativa incidente fora do dossel $\left(\mathrm{PAR}_{\text {incidente }}\right)$, radiação fotossinteticamente ativa transmitida pelo dossel $\left(\mathrm{PAR}_{\text {transmitida }}\right)$ e índice de área foliar ( $\left(\mathrm{AF}_{\mathrm{med}}\right)$ foram medidos mensalmente com ceptômetro em 30 pontos fixos, das 10 às $12 \mathrm{~h}$, horário de maior incidência de radiação solar. Aplicou-se a correlação bivariada de Spearman, ocorrendo correlação positiva e significativa para $I A F_{\text {med }}$ e $P A R_{\text {incidente, e correlação significativa negativa entre } P A R_{\text {incidente }}}$ e $P A R_{\text {transmitida }}$ Os valores de $I A F_{\text {med }}$ oscilaram entre $6,5 \mathrm{~m}^{2} \mathrm{~m}^{-2} \mathrm{em}$ dezembro/2014, período chuvoso, e $2,7 \mathrm{~m}^{2} \mathrm{~m}^{-2}$ em setembro/2015, período seco. Foram comparados valores de IAFmed e IAFLB para os doze meses utilizando regressão linear simples, encontrando coeficiente de determinação acima de 0,7 para 11 dos 12 meses analisados, e aplicou-se teste de Wilcoxon-Mann-Whitney para comparação de médias, não havendo diferença estatística significativa entre os grupos analisados, indicando que a partir da medição de radiações incidentes e transmitidas é viável a aplicação da equação de Lambert-Beer para modelar índices de área foliar para o cerrado stricto sensu, tanto em períodos secos quanto chuvosos.

Palavras-chave: Transmitância; Radiação fotossinteticamente ativa; Parque Urbano.

\section{Evaluation of Lambert-Beer method for estimates of leaf area index in cerrado Mato Grosso}

The study was developed in the Mãe Bonifácia urban park, a cerrado fragment, in the city of Cuiabá/MT, between October/2014 and September/2015, with the objective of evaluating the efficiency of the Lambert-Beer mathematical model for area index estimates leaf (IAF $\left.F_{L B}\right)$. Photosynthetically active radiation incident outside the canopy $\left(\mathrm{PAR}_{\text {incident }}\right)$, photosynthetically active radiation transmitted by the canopy (PAR transmitted) and leaf area index (LAI) were measured monthly with a ceptometer at 30 fixed points, from 10 to $12 \mathrm{~h}$, schedule of higher incidence of solar radiation. Spearman's bivariate correlation was applied, with a positive and significant correlation for $I A F_{\text {med }}$ and $P A R_{\text {incident, }}$ and a significant negative correlation between PAR incident and PAR transmited. The IAF med values ranged from $6.5 \mathrm{~m}^{2} \mathrm{~m}^{-2}$ in December/2014, rainy season, and $2.7 \mathrm{~m}^{2} \mathrm{~m}^{-2}$ in September/2015, dry period. We compared the values of IAF med and IAFLB for the twelve months using simple linear regression, finding a coefficient of determination above 0.7 for 11 of the 12 months analyzed, and Wilcoxon-Mann-Whitney test was applied for comparison of means, there being no significant statistical difference between the analyzed groups, indicating that from the measurement of incident and transmitted radiation it is feasible to apply the Lambert-Beer equation to model leaf area indices for the cerrado stricto sensu, both in dry and rainy periods.

Keywords: Transmittance; Photosynthetically active radiation; Urban Park.

Jonathan Willian Zangeski Novais (DD Universidade de Cuiabá, Brasil http://lattes.cnpq.br/5665663207008673 http://orcid.org/0000-0002-6598-3138 jonathan.novais@kroton.com.br

Levi Pires de Andrade Instituto Federal de Mato Grosso, Brasil http://lattes.cnpq.br/4835803128739663 http://orcid.org/0000-0003-2331-3467 levi.pires@hotmail.com

Angélica Yara Siqueira Universidade de Cuiabá, Brasil http://lattes.cnpq.br/8663210660765952 http://orcid.org/0000-0002-8835-1387 angelica.siq@hotmail.com

\author{
Carlo Ralph De Musis \\ Universidade de Cuiabá, Brasil \\ http://lattes.cnpq.br/2229878954372934 \\ http://orcid.org/0000-0001-6047-1304 \\ carlo.demusis@gmail.com \\ Luciana Sanches (iD) \\ Universidade Federal de Mato Grosso, Brasil \\ http://lattes.cnpq.br/2358137001200356 \\ http://orcid.org/0000-0002-4599-9861 \\ Isanches@ufmt.br \\ Osvaldo Alves Pereira (iD \\ Universidade de Cuiabá, Brasil \\ http://lattes.cnpq.br/4202607809882017 \\ http://orcid.org/0000-0002-2159-4851 \\ osvaldo.pereira@kroton.com.br
}

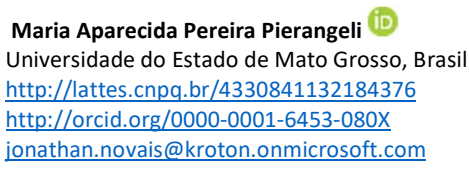

jonathan.novais@kroton.onmicrosoft.com
Referencing this:

NOVAIS, J. W. Z.; ANDRADE, L. P.; SIQUEIRA, A. Y.; MUSIS, C. R.; SANCHES, L.; PEREIRA, O. A.; PIERANGELI, M. A. P. Avaliação do método de Lambert-Beer para estimativas de índice de área foliar no cerrado Mato-Grossense. Revista Ibero Americana de Ciências Ambientais, v.9, n.2, p.19-30, 2018. DOI:

http://doi.org/10.6008/CBPC2179-6858.2018.002.0003 


\section{INTRODUÇÃO}

O bioma Cerrado ocupa aproximadamente dois milhões de quilômetros quadrados do nosso território, distribuídos em áreas do Planalto Central e Nordeste, sendo que em Mato Grosso a área ocupada é de aproximadamente 300 mil $\mathrm{km}^{2}$, o equivalente a $24 \%$ do território nacional (RODRIGUES et al., 2013). Apresentam alta biodiversidade, nele são encontrados diversos ecossistemas com características peculiares e endêmicas. A vegetação desse bioma, em sua maior parte, é constituída por gramíneas, arbustos e árvores esparsas (RODRIGUES et al., 2014). As árvores têm caules retorcidos e raízes longas, que permitem a absorção da água - disponível nos solos do cerrado abaixo de 2 metros de profundidade, mesmo durante a estação seca (DINIZ et al., 2010), assim as folhas recebem grande incidência de raios luminosos na face adaxial (superior), que faz com que aumentem a transpiração. As trocas gasosas efetuadas entre a planta e a atmosfera ocorrem através de microscópicas estruturas denominadas estômatos, localizadas apenas na face abaxial (inferior) fazendo com que a planta tenha menos perda de água (KERBAUY, 2012; RODRIGUES et al., 2016).

A compreensão dos processos morfofisiológicos da vegetação de um bioma e sua interação com os fatores abióticos desse ambiente são imprescindíveis para analisar os fluxos de massa, da energia das superfícies naturais para a atmosfera e consequentemente promover o manejo adequado do sistema soloplanta-atmosfera. $O$ índice de área foliar (IAF) é definido como a razão entre a área foliar de uma população de plantas e a área do solo por ela ocupada. A área foliar expressa a disponibilidade de superfície assimiladora do $\mathrm{CO} 2$ e de interceptação da radiação fotossinteticamente ativa e de perdas de água (transpiração) da população de plantas, tendo relação com a capacidade fotossintética da população vegetal por estar relacionada a área de assimilação de $\mathrm{CO} 2$ e da interceptação de radiação, ou pela redução da própria taxa fotossintética quando altos índices da área foliar indicam perda de água e consequentemente deficiência hídrica (MULLER et al., 2005).

Diferentes variáveis devem ser consideradas para a compreensão dos processos, fluxos e sistemas de um bioma e o cálculo do IAF, por ser uma medida de cobertura vegetal tem significativa relevância ao fornecer informações sobre a troca de massa e energia no sistema solo- planta-atmosfera, diretamente relacionada com a evapotranspiração e produtividade (XAVIER et al., 2003), da importância para vários modelos de produção primária através das escalas e modelos globais de clima, hidrologia, biogeoquímica e ecologia (WANG et al., 2005).

O IAF é parâmetro para compreensão do fornecimento de radiação e a resposta do dossel, e assim do potencial fotossintético e termorregulador da vegetação (ANDRADE et al., 2016). A radiação solar fornece, em média, 1,5 x 10 $18 \mathrm{kWh}$ de energia para a atmosfera terrestre, permitindo à vida da vasta maioria das cadeias tróficas, sendo também o principal responsável pela dinâmica da atmosfera terrestre e pelas características climáticas do planeta (LARCHER, 2004; TAIZ et al., 2004).

Existem várias técnicas para medir o IAF: medição direta por método destrutivo, uso de fotografias hemisféricas ou aparelhos que medem a quantidade de radiação interceptada pela superfície (ceptômetro). 
A utilização de cada técnica dependerá da adequação à formação vegetacional em estudo, associada à possibilidade de fornecerem informações com menor margem de erros, aumentando assim a confiabilidade dos resultados. Diante do exposto é de relevante importância aplicar diferentes técnicas para a coleta de informações e analisar sob a perspectiva de diferentes métodos identificando assim, aqueles que mais apropriadamente se adequam às características de cada bioma.

O modelo matemático de Lambert-Beer relaciona a transmitância (a fração da luz incidente com um comprimento de onda específico, que atravessa uma amostra de matéria) e a absortância (capacidade intrínseca dos materiais em absorver radiação em frequência específica) no IAF de uma comunidade vegetativa, o qual menciona que a equação deve ser linear para determinados intervalos de concentração (NECKEL et al., 2013). Esse modelo consiste na combinação de duas leis, a Lei de Lambert, a qual propõe que a intensidade de luz (monocromática) transmitida decresce exponencialmente com o aumento da espessura da camada do corpo homogêneo e a Lei de Beer, que realizou o mesmo estudo se referindo à concentração de uma solução, mantendo a espessura constante (TAIZ et al., 2004; NOBEL, 2005; BUCHA-NAN, 2015). Dessa forma, o presente trabalho tem como objetivo avaliar a eficiência do modelo matemático de Lambert-Beer para estimativas de índice de área foliar no cerrado stricto sensu.

\section{MATERIAL E MÉTODOS}

\section{Localização dos pontos amostrais}

O Parque urbano Mãe Bonifácia é um fragmento de cerrado localizado na região oeste de Cuiabá, Mato Grosso, entre as coordenadas geográficas $15^{\circ} 34^{\prime} 44^{\prime \prime} \mathrm{S}$ e $56^{\circ} 05^{\prime} 016^{\prime \prime} \mathrm{W}$, com 77,16 hectares de área, Figura 1. Barros (2009), afirma que a variação de altitude está entre 164 e 195m e que a grande diversidade florística se divide em três estratos: a mata ciliar que margeia os córregos, o cerradão afastado do curso d'água e nas regiões mais elevadas o cerrado stricto sensu.

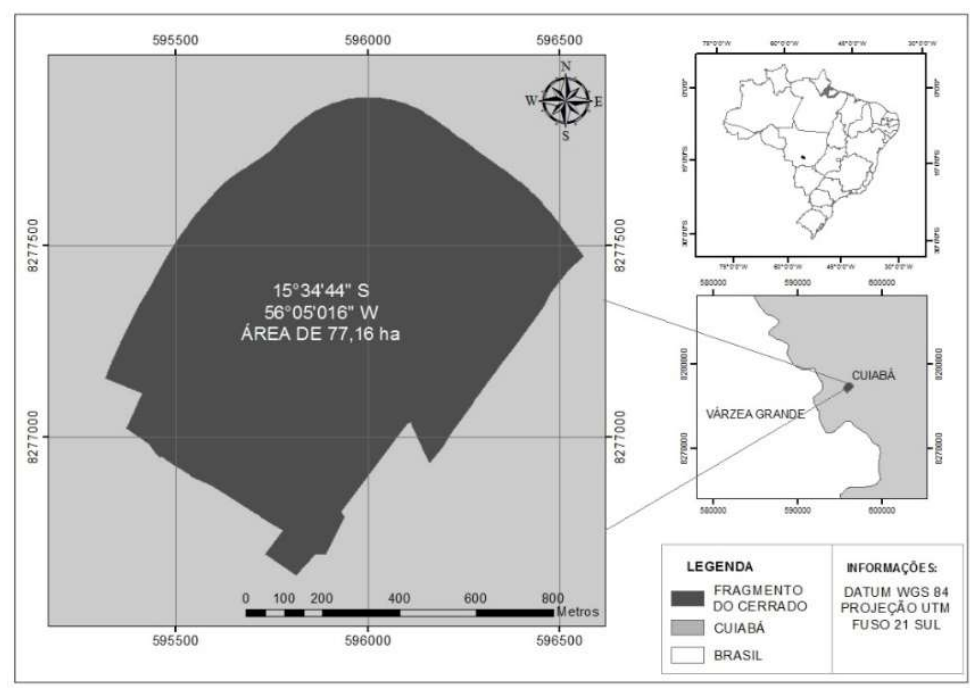

Figura 1: Parque urbano Mãe Bonifácia, Cuiabá/MT, Brasil.

Como forma de preservar uma grande área de cerrado nativo na zona urbana da cidade, lugar outrora ocupado por um quilombo, foi criado em 2000 o primeiro parque urbano do Estado do Mato Grosso, o Parque 
da Cidade Mãe Bonifácia. Segundo a lenda da região, Mãe Bonifácia era uma velha negra que controlava a entrada dos escravos foragidos no quilombo (BARROS et al., 2010). A área do parque foi, primeiramente, transformada em Unidade de Conservação de Interesse Local pela Lei Complementar de Gerenciamento Urbano n. 004, de 24 de dezembro de 1992 (CUIABÁ, 1992). Posteriormente, o Governo do Estado transformou-a em Parque Estadual, pelo Decreto n. 1.470, de 9 de junho de 2000, sendo gerenciada pela Secretaria do Estado de Meio Ambiente (SEMA).

Imediatamente após a entrada principal, o parque possui um amplo estacionamento, a infraestrutura é composta por três praças (Praça do Cerrado com parque de diversões para crianças até 12 anos, Praça da Bandeira como ponto de convívio e a Praça Cívica para a realização de eventos), o parque também é constituído por cinco trilhas, espaço com aparelhos para atividade física e o casarão para a educação ambiental, situados na porção central.

A macrozona urbana da cidade de Cuiabá, MT, com 252 km², localizada no Centro Geodésico da América do Sul, está situada na zona intertropical do Planeta, com clima do tipo Aw, segundo a classificação de Köppen (ALVARES et al., 2013), identificado prioritariamente pela temperatura do ar, apresentando duas estações bem definidas, uma seca, de abril a outubro, e outra chuvosa, de novembro a março, com médias entre $28^{\circ} \mathrm{C}$ e $32^{\circ} \mathrm{C}$ (BARROS et al., 2010).

A pluviosidade média anual fica em torno de $1500 \mathrm{~mm}$, concentrada na estação chuvosa (CURADO et al., 2016). A concentração das chuvas produz contrastes ao longo do ano nas superfícies vegetadas, apresentando nos períodos de secas risco de queimadas, favorecendo uma modificação periódica espacial e temporal no albedo e na umidade do solo e, consequentemente, na variabilidade dos processos físicos da atmosfera da região (BARROS et al., 2010). Esse fragmento de Cerrado é uma área de vegetação nativa circundada por barreiras antrópicas, que impedem significativamente o fluxo de animais, pólen ou sementes. Ambientes isolados podem conter espécies endêmicas devido ao longo tempo de isolamento, o que os torna prioritários para conservação.

Segundo Andrade et al. (2016), o Parque Mãe Bonifácia é um fragmento de cerrado que permanece na sua forma natural e que praticamente não sofreu ações antrópicas relevantes no sentido de alterar suas características biofísicas. As espécies vegetativas mais abundantes no parque são Curatella americana, Albizia niopoides, Anadenanthera colubrina, Samanea Tubulosa, Stryphnodendron barbatimão, Inga Vera and Bowdichia virgilioides. A existência de uma grande área preservada do cerrado original na região central da cidade tem explicação no fato de que, a partir da década de 1970, esta esteve sob a guarda do Exército Brasileiro, servindo como espaço de treinamento militar (BARROS et al., 2010).

No parque foram escolhidos trinta pontos de medição de tal forma a possibilitar a sua caracterização microclimática, sendo estabelecidos de forma aleatória, buscando abranger a diversidade do parque, no que se refere as características pertinentes a sua relação com o mosaico urbano. Os trinta pontos foram demarcados usando estaqueamento e etiquetações e georreferenciados. A região limítrofe ao parque no entorno sudeste/sudoeste possui uma elevada ocupação por residências e prédios, além das vias 
pavimentadas. A região oposta, porção nordeste/noroeste, é cercada pela pavimentação de uma via principal de aproximadamente $30 \mathrm{~m}$ de largura.

\section{Instrumentação e método de estimativa}

Foram coletados dados da radiação fotossinteticamente ativa incidente fora do dossel (PAR incidente), radiação fotossinteticamente ativa transmitida pelo dossel (PAR transmitida $_{2}$, transmitância do dossel, calculada pela divisão da $P A R_{\text {transmitida }}$ pela $P A R_{\text {incidente, }}$ e índice de área foliar medido $\left(I A F_{m e d}\right)$ utilizando um ceptômetro linear modelo (AccuPar-LP80), o qual é constituído por um microprocessador datalogger que interpreta os sinais que chegam à haste metálica, denominada sonda, onde estão instalados os sensores que detectam a radiação. $O$ aparelho mede a radiação fotossinteticamente ativa, na faixa de comprimento de onda de 400 a $700 \mathrm{~nm}$. Os valores de radiação são expressos em micromols por metro quadrado por segundo $\left(\mu \mathrm{mol} . \mathrm{m}^{-2} \cdot \mathrm{s}^{-1}\right)$. Quanto ao IAF calculado pelo método de Lambert-Beer (IAF $\left.\mathrm{LB}_{\mathrm{B}}\right)$, foi utilizada a seguinte equação, com adequação proposta por Monsi et al. (1953):

$$
\mathrm{IAF}_{\mathrm{LB}}=\frac{1}{\mathrm{k}} \cdot \ln \left(\frac{\mathrm{PAR}_{\text {incidente }}}{\mathrm{PAR}_{\text {transmitida }}}\right)
$$

Em que k é o coeficiente de extinção de luz do dossel e em seu cálculo, incluem variáveis como o ângulo zenital e a distribuição dos ângulos de inclinação do dossel. O coeficiente de extinção de luz do dossel depende das características do dossel tanto nos aspectos locais que abrangem fatores ligados a própria vegetação quanto dos aspectos externos vinculados as posições relativas da geometria local com relação à disposição terra-sol, ou seja, dos ângulos: zenital e de declinação solar (SANCHES et al., 2008).

\section{Período de coleta de dados}

Os dados foram coletados nos 30 pontos, uma medição por ponto a cada mês, durante o período de outubro de 2014 a setembro de 2015, no horário das 10 às 12 horas, horário de maior incidência de radiação solar. Foram escolhidos dias que apresentavam pouca ou nenhuma nebulosidade e que não tivesse chovido no dia de forma a minimizar influências externas nas variáveis.

\section{Análise estatística}

Os pressupostos de aderência a distribuição normal para as variáveis $P A R_{\text {transmitida, }} P A R_{\text {incidente, }} I A F_{\text {med }}$ e transmitância foram avaliados teste de normalidade de Shapiro-Wilk (GOTELLI et al., 2011). Uma vez que nem todas as variáveis atenderam os pressupostos de estatística paramétrica, optou-se para verificação de associação pela correlação não-paramétrica de Spearman, mesmo que não necessariamente indiquem uma correlação linear e nem uma proporção de variância comum entre as variáveis, podendo ser considerados como índices de monotonicidade, mostrando uma tendência comum das variáveis em termos de crescimento ou decrescimento, indicando a tonicidade das variáveis (BUNCHAFT et al., 1999). Após o cálculo do IAF $F_{L B}$, com a intenção de validação do modelo, foram comparados com os dados de IAF medidos (IAF med), utilizando regressão linear simples e teste de comparação de médias Wicoxon-Mann-Whitney. 


\section{RESULTADOS}

\section{Radiação fotossinteticamente ativa incidente, transmitida e índice de área foliar}

Foi apresentado na figura 2 os resultados para radiação fotossinteticamente ativa incidente ( $\left.P A R_{\text {incidente }}\right)$, transmitida $\left(P A R_{\text {transmitida }}\right)$, índice de área foliar medido $\left(\mathrm{IAF}_{\mathrm{med}}\right)$ e transmitância do dossel a passagem de radiação fotossinteticamente ativa.

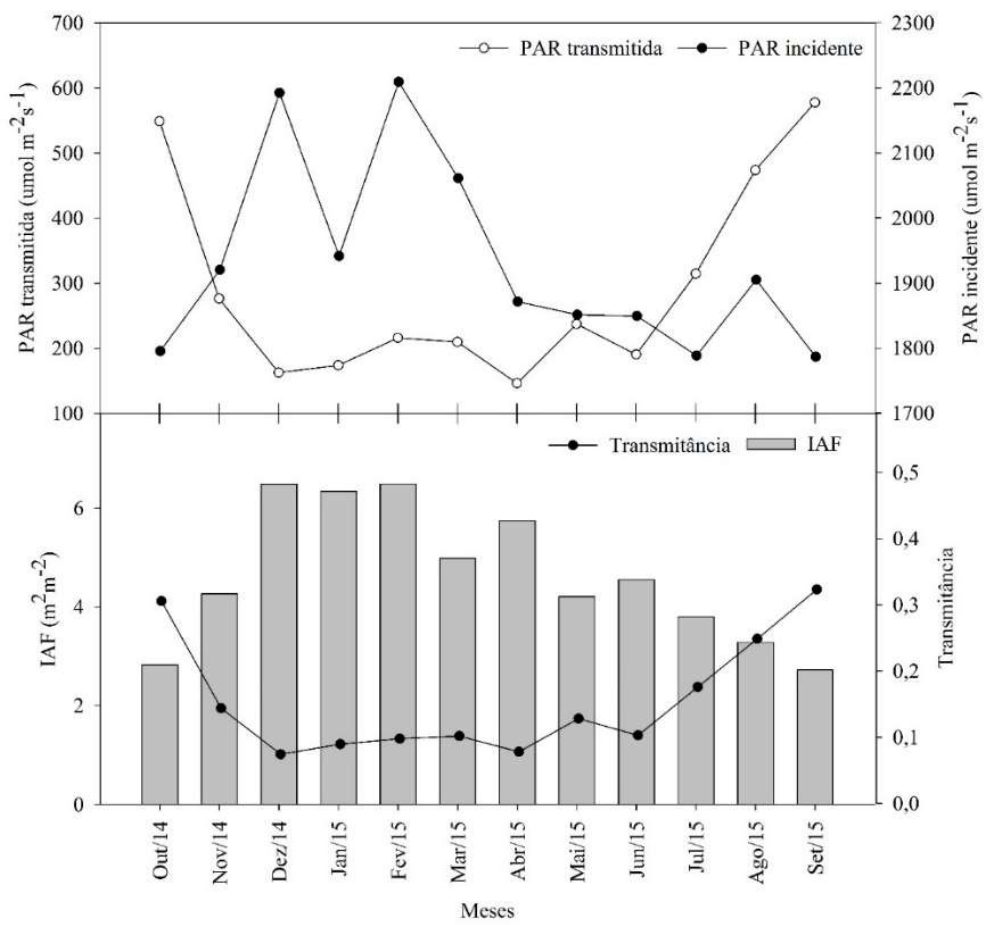

Figura 2: Médias mensais da PARtransmitida, $P A R$ incidente, $I A F_{\text {med }}$ e transmitância do dossel, nos meses de outubro de 2014 a setembro de 2015, para o parque urbano Mãe Bonifácia, em Cuiabá-MT, Brasil.

Nota-se uma resposta no $\mathrm{IAF}_{\text {med }}$ com o início das chuvas em novembro de 2014, apresentando em dezembro de 2014 os maiores valores de $\mathrm{IAF}_{\mathrm{med}}, 6,5 \mathrm{~m}^{2} \mathrm{~m}^{-2}$. O IAF é determinante para a emissão da radiação fotossinteticamente ativa transmitida pelo dossel e sua transmitância, em que IAF menores permitem uma maior passagem de luz. Em setembro de 2015, período seco, ocorreu o menor valor médio, aproximadamente $2,7 \mathrm{~m}^{2} \mathrm{~m}^{-2}$. Observa-se que de outubro a novembro de 2014 , início da estação chuvosa, houve um aumento de $33,8 \%$ nos valores do $I A F_{\text {med, }}$ o que levou a uma queda de $49,6 \%$ na PAR transmitida e na transmitância, de 0,31 abaixou para 0,14. Estes valores continuaram a decrescer proporcionalmente ao aumento do $I A F_{\text {med }}$ durante as máximas de pluviosidade na estação chuvosa. Entre os meses de dezembro de 2014 e junho de 2015 os valores da PAR transmitida, período no qual estão compreendidos os maiores índices pluviométricos da estação chuvosa, oscilou $91 \mu \mathrm{molm}^{2} \mathrm{~s}^{-1}$, estando o valor mínimo em abril, $146,12 \mu \mathrm{molm} \mathrm{s}^{2}$ 1 e o máximo em maio, $237,20 \mu \mathrm{molm}^{2} \mathrm{~s}^{-1}$. Os menores valores mensais da transmitância foram correspondentes aos meses da PAR transmitida, sendo que o valor mínimo foi identificado em dezembro de 2014, $0,07 \mu \mathrm{molm}^{2} \mathrm{~s}^{-1}$, e o valor máximo em maio, $0,13 \mu \mathrm{molm}^{2} \mathrm{~s}^{-1}$, uma oscilação de $0,06 \mu \mathrm{molm}^{2} \mathrm{~s}^{-1}$. De junho a julho, período que inicia a estação seca com considerável escassez hídrica, observa-se um aumento de 39,35 $\%$ na PAR transmitida, pois de $190,27 \mu \mathrm{molm}^{2} \mathrm{~s}^{-1}$ em junho elevou-se para $314,47 \mu \mathrm{molm}^{2} \mathrm{~s}^{-1}$ em julho, 
consequentemente uma ascendência de 0,1 para 0,18 na transmitância. De julho a setembro de 2015, período de maior déficit hídrico, a PAR transmitida ascendeu para $577,67 \mu \mathrm{molm}^{2} \mathrm{~s}^{-1}$ e a transmitância para 0,32 . Essa sazonalidade observada para dados de IAF, também foi observada por Resende et al. (2010) em floresta de transição Amazônia/cerrado em Sinop/MT, em que os valores oscilaram em média entre $5,5 \mathrm{~m}^{2} \mathrm{~m}^{-2}$ no período seco e $8 \mathrm{~m}^{2} \mathrm{~m}^{-2}$ para período chuvoso.

Dessa forma observa-se, que os meses em que ocorreram os maiores valores de radiação fotossinteticamente transmitida, outubro de $2014,548,9 \mu \mathrm{molm}^{2} \mathrm{~s}^{-1}$, e setembro de $2015,577,67 \mu \mathrm{molm}^{2} \mathrm{~s}^{-}$ 1, e transmitância do dossel, 0,31 e 0,32 respectivamente, coincidiram com os meses de menores índices de área foliar, 2,82 $\mathrm{m}^{2} \mathrm{~m}^{-2}$ outubro de 2014 e $2,7 \mathrm{~m}^{2} \mathrm{~m}^{-2}$ em setembro de 2015 , demonstrando uma correlação negativa entre as variáveis, -0,860 para $I A F_{\text {med }}$ e $P A R_{\text {transmitida }}$ e -0,944 para $I A F_{m e d}$ e transmitância. Vilani et al. (2007) e Novais (2013) encontraram correlação significativa entre a radiação que ultrapassa o dossel e a transmitância em floresta de transição Amazônia-Cerrado e Pantanal, respectivamente. Pereira et al. (2013) ao estimarem o fluxo de $\mathrm{CO}_{2}$ e evapotranspiração em área de floresta no norte do Pantanal Mato-grossense, constataram que a evapotranspiração esteve fortemente correlacionada com a $\operatorname{PAR}_{\text {incidente }}(r=0,97)$ e que em dias de céu parcialmente nublado os valores da PAR incidente foram em média $800 \mu \mathrm{molm}^{2} \mathrm{~s}^{-1}$, e em dias de céu limpo foram de $2240 \mu \mathrm{molm}^{2} \mathrm{~s}^{-1}$.

Houve sazonalidade característica para a radiação fotossinteticamente ativa incidente, com maiores valores no verão, aproximadamente $2200 \mu \mathrm{molm}^{2} \mathrm{~s}^{-1}$, mesmo padrão encontrado por Novais et al. (2015; 2016) para radiação global em estudo no Pantanal a 200km de Cuiabá-MT e por Andrade et al., (2014) em estudo na mata Atlântica em Alagoas.

O menor valor médio de transmitância, 0,1, ocorreu em junho de 2015. Valores menores de transmitância geralmente ocorrem para os maiores valores do ângulo solar zenital, porque quanto maior o ângulo zenital maior será o caminho percorrido pela radiação dentro do dossel, aumentando a chance de ocorrer uma absorção por folhas e galhos (SENNA et al., 2005; SPOLADOR et al., 2006). Pertinente se torna mencionar que estando a região em estudo situada na zona intertropical do planeta e muito próxima ao equador, o ângulo zenital é menor, em consequência a radiação solar incidente na superfície é máxima porque, nessa situação, a sua trajetória através da atmosfera é mais curta.

Uma radiação solar incidente máxima com um alto IAF ocasiona uma alta PAR incidente chegando a 2209,17 $\mu \mathrm{molm}^{2} \mathrm{~s}^{-1} \mathrm{em}$ fevereiro de 2015. Os menores valores para a PAR incidente foram observados nos meses que compreendem a estação seca, outubro/2014, 1795,41 $\mu \mathrm{molm}^{2} \mathrm{~s}^{-1}$, julho/2015, 1788,57 $\mu \mathrm{molm}^{2} \mathrm{~s}^{-1} \mathrm{e}$ setembro/2015, 1786,70 $\mathrm{mmolm}^{2} \mathrm{~s}^{-1}$, evidenciando uma queda na atividade fotossintética das plantas, corroborada pela diminuição dos valores de IAF no mesmo período, outubro/2014, 2,82 $\mathrm{m}^{2} \mathrm{~m}^{-2}$, julho/2015, $3,8 \mathrm{~m}^{2} \mathrm{~m}^{-2}$, agosto/2015, 3,28 $\mathrm{m}^{2} \mathrm{~m}^{-2}$ e setembro/2015, 2,72 $\mathrm{m}^{2} \mathrm{~m}^{-2}$ e comprovada pelo aumento simultâneo dos valores de transmitância 0,31, 0,18, 0,25 e 0,32 respectivamente. Na tabela 1 observa-se a correlação de Spearman entre as variáveis analisadas. 
Tabela 1: Correlação de Spearman entre radiação fotossinteticamente ativa transmitida pelo dossel (PARtransmitida),

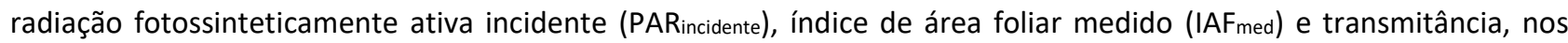
meses de outubro de 2014 a setembro de 2015, para o parque urbano Mãe Bonifácia, em Cuiabá/MT, Brasil.

\begin{tabular}{|l|l|l|l|}
\hline & $\mathrm{PAR}_{\text {incidente }}$ & $\mathrm{IAF}_{\text {med }}$ & Transmitância \\
\hline $\mathrm{PAR}_{\text {transmitida }}$ & $-0,573^{1}$ & $-0,860^{1}$ & $0,965^{1}$ \\
\hline & $0,048^{2}$ & $0,000^{2}$ & $0,000^{2}$ \\
\hline $\mathrm{PAR}_{\text {incidente }}$ & & $0,832^{1}$ & $-0,720^{1}$ \\
\hline & & $0,000^{2}$ & $0,007^{2}$ \\
\hline $\mathrm{IAF}_{\text {med }}$ & & & $-0,944^{1}$ \\
\hline & & & $0,000^{2}$ \\
\hline
\end{tabular}

${ }^{1}$ Coeficiente de correlação de Spearman. ${ }^{2}$ P-valor a um nível de significância de 0,05.

Observa-se na Tabela 1 que ocorreu correlação positiva e significativa para IAF $F_{\text {med }}$ e $P A R_{\text {incidente, }}$ 0,832, indicando que na época em que se incide mais radiação no local coincide com o momento em que a vegetação possui maior quantidade de folhas. Por esse mesmo motivo, a correlação entre $P A R_{\text {incidente }}$ e PAR transmitida foi significativa e negativa, $-0,573$, uma vez que a presença de folhas diminui a quantidade de radiação que consegue atravessar o dossel.

\section{Regressão linear e teste de Wicoxon-Mann-Whitney entre IAF medido e calculado pelo método de Lambert-Beer}

$\mathrm{Na}$ figura 3, fez-se regressão linear entre índice de área foliar medido pelo ceptômetro $\mid A F_{\text {med }}$ e calculado pelo método de Lambert-Beer, IAF intuito de avaliar o coeficiente de determinação entre as variáveis.

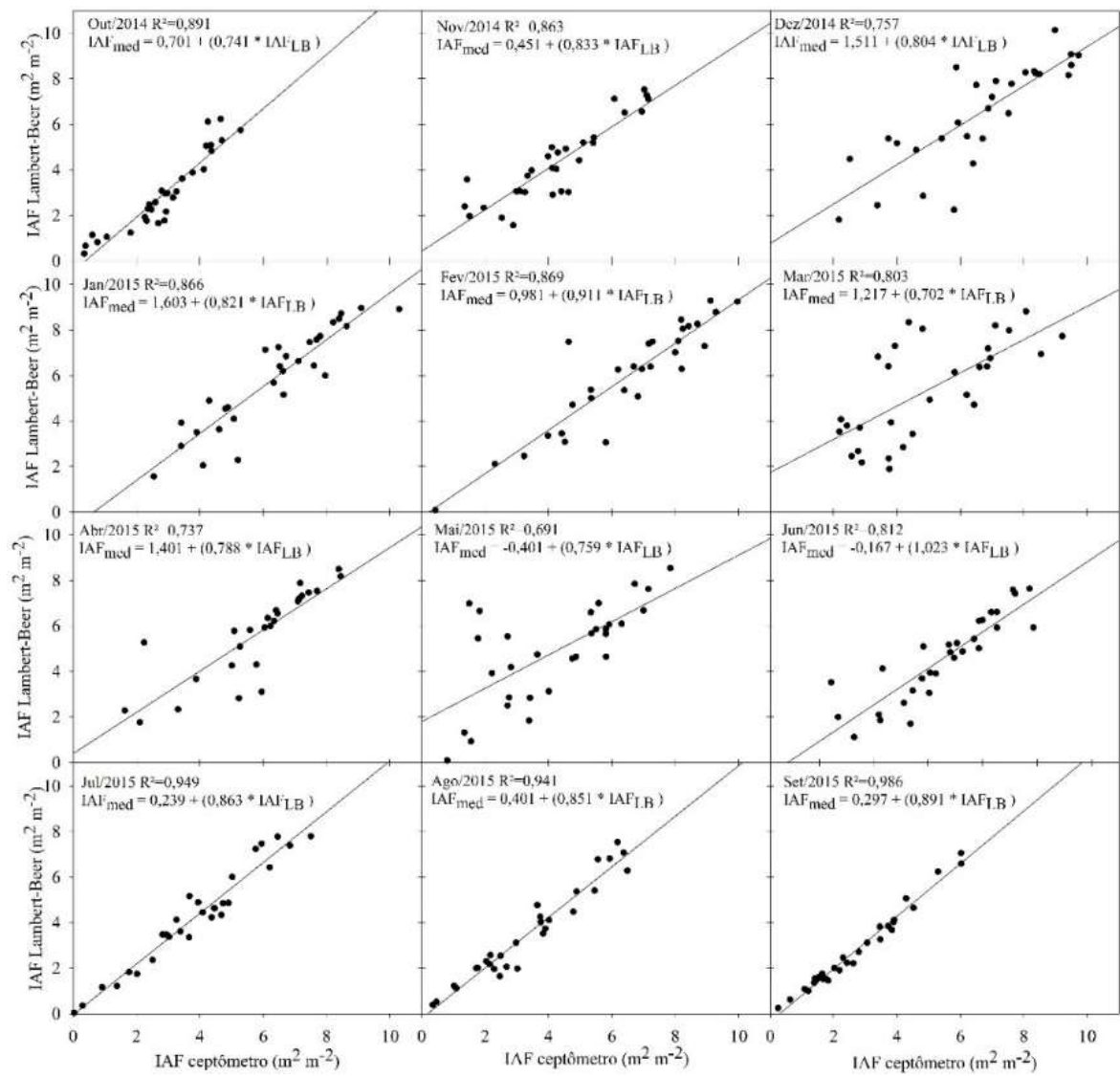

Figura 3: Regressão linear para índice de área foliar medido pelo ceptômetro (IAFmed) e calculado pelo método de Lambert-Beer (IAFLB) nos meses de outubro de 2014 a setembro de 2015, para o parque urbano Mãe Bonifácia, em Cuiabá/MT, Brasil. 
Com exceção ao mês de maio de 2015, os resultados para o coeficiente de determinação foram satisfatórios, apresentando valores maiores que 0,7 para o restante dos meses, indicando que o modelo de regressão linear é adequado. Os menores valores para o mês de maio podem ter sido causados por nebulosidade e problemas com galhos e troncos nas medições da radiação fotossinteticamente ativa (SANCHES et al., 2008). Já para a comparação entre as medianas dos grupos, teste de Wicoxon-MannWhitney, encontrou-se $p$-valor de 0,740 , não havendo assim diferença estatística significativa entre os IAF ${ }_{L B}$ e $I A F_{\text {med. }}$.

\section{DISCUSSÃO}

Observa-se na figura 2 que durante a estação das chuvas a planta atinge o máximo da sua atividade fotossintética, pois os maiores valores de diferença entre a $P A R_{\text {incidente }}$ e a $P A R_{\text {transmitida }}$ foram encontrados nos meses correspondentes a estação chuvosa. Em dezembro de 2014, onde ocorreu o maior índice pluviométrico do período em estudo, identificou-se a maior diferença, 2029,76 $\mu \mathrm{molm}^{2} \mathrm{~s}^{-1}$ e em setembro de 2015, onde ocorreu o menor índice pluviométrico do período em estudo, essa diferença esteve em 1209,03 $\mu \mathrm{molm} \mathrm{s}^{-1}$.

No final da estação chuvosa inicia o fenômeno da senescência foliar, um processo metabólico ocasionado pelo redirecionamento dos nutrientes para outras zonas da planta, que no Cerrado ocorre apenas na parte aérea da planta culminando na abscisão foliar (MAILLARD et al., 2015). Essa abscisão foliar possibilita uma economia considerável na perda de água no processo de transpiração e na disponibilidade de nutrientes para manter uma superfície foliar com baixa produtividade fotossintética devido ao acentuado déficit hídrico na estação da seca.

Os menores índices de transmitância, figura 2, ocorreram na estação chuvosa, com valor mínimo de 7\% em dezembro de 2014 e valor máximo de 13\% em maio de 2015. Sendo a transmitância a fração da luz incidente em um comprimento de onda específico, que passa por uma amostra de matéria é cabível a correlação de um menor índice de transmitância no período em que ocorre maior IAF, visto que ocorre um aumento no volume de biomassa foliar da planta, portanto maior é a amostragem da matéria por onde a incidência da luz irá passar.

Nesse período de seca é alto o índice de queimadas urbanas em Cuiabá-MT, conforme dados do Instituto Nacional de Pesquisas Espaciais - INPE, foram registrados 1584 focos de incêndio para o mês de setembro de 2015, essa grande quantidade de material particulado suspenso na atmosfera promove uma diminuição na PAR incidente, pois parte do fluxo de radiação que chega na atmosfera é refletido e/ou sofre espalhamento. Januário et al. (1992) estimaram para floresta tropical úmida na Amazônia uma transmitância da radiação de 4,7\%. Já estudos realizados por Leitão (1999) e Senna et al., (2005) apresentaram valor de transmitância de 1,3 \% e 3\%, respectivamente. Novais (2013) observou valores de transmitância no Pantanal mato-grossense que variam de $1 \%$ em períodos mais úmidos a $16 \%$ nos mais secos.

O cerrado devido sua vegetação mais esparsa possibilitou transmitâncias de $32 \%$ no período mais seco a 7\% nos períodos mais úmidos. Esse comportamento diferenciado é explicado, pela ocorrência ou não, 
de clareiras, que modificam significativamente o regime da PAR no interior da floresta (Sansevero et al., 2006).

Quanto as correlações entre as variáveis, observa-se na tabela 1 que ocorreu correlação positiva e significativa para IAF med e PAR incidente, 0,832 , indicando que na época em que se incide mais radiação no local coincide com o momento em que a vegetação possui maior quantidade de folhas. Por esse mesmo motivo, a correlação entre $P A R_{\text {incidente }}$ e PAR transmitida foi significativa e negativa, $-0,573$, uma vez que a presença de folhas diminui a quantidade de radiação que consegue atravessar o dossel.

Para definição da validade do método para o cerrado, tanto a regressão linear, quanto o teste de Wilcoxon-Mann-Whitney, indicaram que para a localidade, utilizando dados de radiação fotossinteticamente ativa incidente e transmitida pelo dossel, o método de Lambert-Beer pode ser utilizado com boa aproximação para estimativas de índice de área foliar, tanto para períodos de seca quanto períodos úmidos, sendo uma boa alternativa para estudos de dinâmica de dossel.

\section{CONCLUSÕES}

Os valores de $I A F_{\text {med }}$ Oscilaram entre $6,5 \mathrm{~m}^{2} \mathrm{~m}^{-2}$ em dezembro de 2014 e $2,7 \mathrm{~m}^{2} \mathrm{~m}^{-2}$ em setembro de 2015, ocorrendo correlação positiva e significativa para $I A F_{\text {med }}$ e $P A R_{\text {incidente, e correlação significativa negativa }}$ entre $P A R_{\text {incidente }}$ e $P A R_{\text {transmitida. }}$ Os resultados obtidos indicam que a partir da medição de radiações incidentes e transmitidas é viável a aplicação da equação de Lambert-Beer para modelar índices de área foliar para o cerrado stricto sensu, tanto em períodos secos quanto úmidos, encontrando em 11 dos 12 meses coeficientes de determinação maiores que 0,7 entre o índice de área foliar medido e modelado e por não haver diferença estatística significativa entre os grupos analisados.

\section{REFERÊNCIAS}

ALVARES, C. A.; STAPE, J. L.; SENTELHAS, P. C.; GONÇALVES, J. L. M.; SPAROVEK, G.. Köppen's climate classification map for Brazil. Meteorologische Zeitschrift, Zurich, v.22, n.6, p.711-728, 2013. DOI: http://10.1127/09412948/2013/0507

ANDRADE, A. M. D.; MOURA, M. A. L.; SANTOS, A. B.; CARNEIRO, R. G.; SILVA JUNIOR, R. S.. Radiação fotossinteticamente ativa incidente e refletida acima e abaixo do dossel de floresta de mata Atlântica em Coruripe, Alagoas. Revista brasileira de meteorologia, São Paulo, v.29, n.1, p.68-79, 2014. DOI: http://dx.doi.org/10.1590/S010277862014000100007

ANDRADE, L. P.; NOVAIS, J. W. Z.; DE MUSIS, C. R.; SANCHES, L.; PEREIRA, S. P.. Efeitos de borda sobre o microclima de um parque ecológico urbano em Cuiabá/MT. Revista Estudo e Debate, Lajeado, v.23, n.2, 2016. DOI: http://dx.doi.org/10.22410/issn.1983-036X.v23i2a2016.107

BARROS, M. P.. Estudo microclimático e topofílico no Parque Mãe Bonifácia da cidade de Cuiabá/MT (dissertação) - Mestrado em Física Ambiental da Universidade Federal de Mato Grosso, Cuiabá, 2009.
BARROS, M. P. B.; DE MUSIS, C. R.; HORNICK, C.. Parque da cidade Mãe Bonifácia, Cuiabá/MT: Topofilia e amenização climática em um fragmento de Cerrado urbano. Sociedade Brasileira de Arborização Urbana, Piracicaba, v.5, n.2, p.0118,2010

BUCHA-NAN, B. B.; GRUISSEM, W.; JONES, R. L. Biochemistry and molecular biology of plants. 2 ed. American Society of Plant Physiologists: Rockville, 2015.

BUNCHAFT, G.; KELLNER, S. R. O. Estatística sem mistério. 2 ed. Petrópolis: Vozes, 1999.

CUIABÁ. Lei complementar n.004 de 24 de dezembro de 1992. Institui o código sanitário e de posturas do município, o código de defesa do meio ambiente e recursos naturais, o código de obras e edificações e dá outras providências. Cuiabá, 1992.

CURADO, L. F. A.; MUSIS, C. R.; CUNHA, C. R.; RODRIGUES, T. R.; PEREIRA, V. M. R.; NOGUEIRA, J. S.; SANCHES, L.. Modeling the reflection of Photosynthetically active radiation in a monodominant floodable forest in the Pantanal of Mato Grosso State using multivariate statistics and neural networks. Academia brasileira de ciências, v.88, 
n.3, Rio de Janeiro, 2016. DOI:

http://dx.doi.org/10.1590/0001-3765201620150176

DINIZ, I. R.; FILHO, J. M.; MACHADO, R. B.; CAVALCANTI, R. B. Cerrado, conhecimento quantitativo como subsídio para ações de conservação. 1 ed. Brasília: Thesaurus, 2010.

GOTELLI, N. J.; ELLISON, A. M.. Princípios de estatística em ecologia em estatística. Porto Alegre: Artmed, 2011.

LARCHER, W.. Ecofisiologia Vegetal. São Carlos: Rima, 2004.

LEITÃO, M. M. V. B. R.. Balanço de radiação em três ecossistemas da floresta amazônica: campina, campinarana e mata densa. Revista Brasileira de Geofísica, v.17, n.1, Rio de Janeiro, 1999.

KERBAUY, G. B.. Fisiologia Vegetal. 2 ed. Rio de Janeiro: Guanabara Koogan, 2012.

MAILLARD, A.; DIQUÉLOU, S.; BILLARD, V.; LAINÉ, P.; GARNICA, M.. Leaf mineral nutrient remobilization during leaf senescence and modulation by nutrient deficiency. Frontiers in Plant Science, v. 6, n.1, Rockville, 2015. DOI: http://10.3389/fpls.2015.00317

MONSI, M.; SAEKI, T. Über den Lichtfakor in den Pflanzengesellschaften, seine Bedeutung für die Stoff produckion. Japanese Journal of Botany, v. 14, n.1, p.22-52, 1953.

NECKEL, A.; GOELLNER, E.; SOSSMEIER, S.G. Os recursos hídricos e a educação ambiental. Passo Fundo: Goellner, 2013.

NOBEL, P. S.. Physicochemical and Environmental Plant Physiology, 3 ed. San Diego: Elsevier/Academic Press, 2005.

NOVAIS, J. W. Z.. Variação espaço-temporal dos fluxos radiativos abaixo do dossel em floresta sazonalmente alagada no Pantanal Mato-Grossense. Tese (Doutorado em Física Ambiental) - Universidade Federal de Mato Grosso, Cuiabá, 2013.

NOVAIS, J. W. Z.; SANCHES, L.; SILVA, L. B.; MACHADO, N. G.; AQUINO, A. M.; RODRIGUES, T. R. Variação horária e sazonal da radiação solar incidida e refletida e suas relações com variáveis micrometeorológicas no Pantanal Norte Matogrossense. Revista Brasileira de Ciências Ambientais, Rio de Janeiro, v.38, p.96-108, 2015. DOI: http://10.5327/Z2176947820150053

NOVAIS, J. W. Z.; SANCHES, L.; SILVA, L. B.; MACHADO, N. G.; AQUINO, A. M.; PINTO JUNIOR, O. B. Albedo do solo abaixo do dossel em área de Vochysia Divergens Pohl no norte do Pantanal. Revista Brasileira de Meteorologia, São José dos Campos, v.31, n.2, p.157-166, 2016. DOI: http://dx.doi.org/10.1590/0102-778631220150001

PEREIRA, O. A.; BIUDES, M. S.; NOGUEIRA, J. S.; SEIXAS, G. B.; ZANELLA, P. H. A.. Determinação do Fluxo de CO2 no Norte do Pantanal Mato-Grossense. Revista Brasileira de Meteorologia, São José dos Campos, v.28, n.3, p.341-351, 2013. DOI: http://dx.doi.org/10.1590/S010277862013000300010
RESENDE, S. D.; LOBO, F. A.; DALMAGRO, H. J.; BIUDES, M. S.; PINTO JUNIOR, O. B.; NOGUEIRA, J. S.; VOURLITIS, G. L.. Avaliação de dois métodos para estimativa de índice de área foliar em floresta de transição Amazônia-Cerrado. Ciência e Natura, Santa Maria, v. 32, n.2, p.183-195, 2010.

RODRIGUES, T. R.; PAULO, S. R.; NOVAIS, J. W. Z.; CURADO, L. F. A.; NOGUEIRA, J. S. Temporal patterns of energy balance for a brazilian tropical savanna under contrasting seasonal conditions. International Journal of Atmospheric Sciences, v.13, n.1, 2013. DOI: http://dx.doi.org/10.1155/2013/326010

RODRIGUES, T. R.; PAULO, S. R.; NOVAIS, J. W. Z.; CURADO, L. F. A.; NOGUEIRA, J. S. Seasonal variation in energy balance and canopy conductance for a tropical savanna ecosystem of south-central Mato Grosso, Brazil. Journal of Geophysical Research-Biogeosciences, v. 119, n.1, p. 1-13, 2014. DOI: http://10.1002/2013JG002472

RODRIGUES, T. R.; VOURLITIS, G. L.; LOBO, F. A;. SANTANNA, F. B.; ARRUDA, P. H. Z.; NOGUEIRA, J. S.. Modeling canopy conductance under contrasting seasonal conditionsfor a tropical savanna ecosystem of south central Mato Grosso, Brazil. Agricultural and Forest Meteorology, v. 218-219, p.218-229, 2016. DOI: https://doi.org/10.1016/j.agrformet.2015.12.060

SANCHES, L.; ANDRADE, N. L. R.; NOGUEIRA, J. S.; BIUDES, M. S.; VOURLITIS, G. L.. Índice de área foliar em floresta de transição Amazônia cerrado em diferentes métodos de estimativa. Ciência e Natura, Santa Maria, v.30, n.1, p.57-69, 2008 .

SANSEVERO, J. B. B.; PIRES, J. P.; PEZZOPANE, J. E. M.. Caracterização ambiental e enriquecimento da vegetação de áreas em diferentes estágios sucessionais (pasto, borda, clareira e floresta). Revista científica eletrônica de engenharia florestal, Garça, v.7, n.1, 2006.

SENNA, M. C. A.; COSTA, M. H.; SHIMABUKURO, Y. E.. Fraction of photosynthetically active radiation absorbed by Amazon tropical forest: A comparison of field measurements, modeling, and remote sensing. Journal of Geophysical Research, v.110, 2005. DOI: http://10.1029/2004JG000005

SPOLADOR, J.; SANCHES, L.; COSTA, M. H.. Radiação fotossinteticamente ativa em uma floresta de transição Cerrado-Amazônia. Revista Brasileira de Meteorologia, São José dos Campos, v.21, n.3b, p.301-307, 2006.

TAIZ, L.; ZEIGER, E. Fisiologia Vegetal. 3 ed. Porto Alegre: Artemed, 2004.

VILANI, M. T.; SANCHES, L.; COSTA, M. H.; GAIO, D. C.; NOGUEIRA, S. J.. Estimativa da absortância da radiação fotossinteticamente ativa de uma vegetação de transição floresta Amazônica-cerrado por três métodos. Revista Brasileira de agrometeorologia, Santa Maria, v.15, n.1, p.289-298, 2007.

WANG, Q.; ADIKU, S.; TENHUNEN, J.; GRANIER, A.. On the relationship of NDVI with leaf area index in a deciduous forest site. Remote Sensing of Environment, v. 94, n.2, pag. 244-255, 2005. DOI: http://10.1016/j.rse.2004.10.006 
XAVIER, A. C.; VETTORAZZI, C. A.. Índice de Área Foliar de Coberturas em uma Microbacia Hidrográfica Subtropical.
Scientia Agrícola, Piracicaba, v.60, n.3, p.425-431, 2003

DOI: http://dx.doi.org/10.1590/S0103-90162003000300002

A CBPC - Companhia Brasileira de Produção Científica (CNPJ: 11.221.422/0001-03) detém os direitos materiais desta publicação. Os direitos referem-se à publicação do trabalho em qualquer parte do mundo, incluindo os direitos às renovações, expansões e disseminações da contribuição, bem como outros direitos subsidiários. Todos os trabalhos publicados eletronicamente poderão posteriormente ser publicados em coletâneas impressas sob coordenação da Sustenere Publishing, da Companhia Brasileira de Produção Científica e seus parceiros autorizados. Os (as) autores (as) preservam os direitos autorais, mas não têm permissão para a publicação da contribuição em outro meio, impresso ou digital, em português ou em tradução. 